Institute of $\mathbf{F}_{\text {ood and }} \mathbf{A}_{\text {gricultural }} \mathbf{S}_{\text {ciences }}$

\title{
Water and Environmental Considerations for the Design and Development of Citrus Groves in Florida ${ }^{1}$
}

Brian Boman, Nigel Morris, and Mark Wade ${ }^{2}$

\section{Introduction}

There are many factors that are involved in water management of citrus in Florida. However, since no two groves are the same, the optimum water management strategy for each grove has to consider the specific conditions of that particular grove. Not only do the physical grove conditions differ from site to site, but the experiences and management philosophies of each manager differ. As a result, there are no hard and fast rules that delineate good and poor water management for Florida citrus. All factors need to be evaluated together in order to accurately assess potential water management strategies for a particular site. These factors may include the following:

1. Soil survey

2. Boundary survey

3. Topographic survey
- Ground surface elevation

- Aerial photographs

4. Wetland delineations

5. Irrigation source and Consumptive Use Permit

6. Surface water management plan

- On-site ditches and canals

- Above or below ground reservoirs

- Drainage pump station

- Off-site roadway or drainage improvements

- Off-site drainage through or around site

7. Construction plans and specifications

- Clearing

1. This is Circular 1419, one of a series of the Department of Agricultural and Biological Engineering, Florida Cooperative Extension Service, Institute of Food and Agricultural Sciences, University of Florida. Publication date: August 2002. Please visit the EDIS Web site at http://edis.ifas.ufl.edu for additional publications related to citrus water management. This document can be accessed as http://edis.ifas.ufl.edu/CH163.

2. Brian Boman, Associate Professor, Department of Agricultural and Biological Engineering, Indian River REC-Ft. Pierce; Nigel Morris, AMS Engineering and Environmental, Inc., Punta Gorda, FL; and Mark Wade, Assistant Professor, Food and Resource Economics Department, Indian River REC-Ft. Pierce. University of Florida Cooperative Extension Service, Institute of Food and Agricultural Sciences, Gainesville, FL 32611. 
- Grading and bedding

- Drainage, including ditches, reservoirs and dikes, culverts, discharge structures, emergency overflow sructures, and pump stations

8. Permits

- County or local municipality

- Local Water Control District

- Regional water management district

1. Surface water management/natural resources

2. Consumptive use of irrigation water

3. District right-of-way permit

- Florida Department of Environmental Protection (FDEP)

- U.S. Corps of Engineer

- Florida Department of Transportation (FDOT) for drainage or access rights of way

\section{Soil Considerations}

The rolling sand hills in Central Florida (the Ridge) are largely well drained. These light sandy soils are usually underlain by a sandy clay layer. Clay or organic matter in the soil helps to retain moisture and nutrients for use by the trees. The Indian River and Southwest Florida citrus production areas are generally poorly drained flatwoods soils. These are usually white sands underlain by an organic layer or hardpan that inhibits internal drainage. The water table in these soils is normally at or near the soil surface and must be lowered artificially to facilitate citrus growth.

Many of the poorly drained coastal flatwoods areas are underlain with shell, marl, or limestone. The oolitic limestone soils of extreme South Florida are predominately found in parts of Dade, Broward, and Monroe counties. Both soil types tend to be quite alkaline and may need special consideration in the cultural program. Soil types, drainage, texture, and the amount of organic matter in flatwoods soils can vary markedly even within a given area. The importance of a careful survey prior to planting cannot be overemphasized as this may help to prevent mistakes that the grower will have to contend with for the life of the grove.

\section{Location}

There are many other factors that govern the suitability of a site for citrus. Access to the property, land value, taxes, and water may be as important as soil type or freeze potential. Access to any property is quite important, especially in selecting a grove site. Heavy equipment will need to be moved in and out of the grove periodically and roads need to be in good condition to accommodate this traffic. Distance from a processing or packing facility should also be considered as this may influence hauling costs.

Land value and taxes should also be considered when selecting grove sites. Some land is simply too valuable to grow citrus on and good grove land may be desirable for commercial or residentiial development, especially if the area is near a population center. Land purchased at a high price is also likely to carry high property taxes. Property tax may vary from area to area and should be thoroughly checked out. Special exemptions for agriculture may not always be in effect.

\section{Land Preparation}

On well-drained sandy soils of the Central Florida Ridge (soil series such as Astatula, Archbold, Tavares, Candler, etc.), planting on unaltered ground is adequate. In areas of native vegetation, the main requirement for land preparation is to clear, pile and burn the existing vegetation. Most areas can be cleared with front-end loaders fitted with root rakes. Some may require heavier equipment, such as bulldozers or backhoes for pine stump removal. Further physical alteration of the land surface is generally unnecessary. Soil amendments are usually required and should be guided by the results of soil testing. On previously cleared land, the chief requirement for land preparation would be discing. 
In poorly drained sandy soils of the South Florida Flatwoods (soil series such as Basinger, Immokalee, Myakka, Pineda, Riviera, Smyrna, Wabasso, Winder, etc.), control of the naturally high water table and rapid removal of excess surface water from rainfall are essential in addition to land clearing. Trees (long leaf pine, slash pine and oaks), including stumps and shrubs (palmetto, wax myrtle, etc.) can be cleared in a single operation with heavy machinery, then piled and burned. Alternatively, pines can be sold as timber, after which stumps must be removed with a backhoe. Native flatwoods soils will usually require adjustment of $\mathrm{pH}$ via the application of lime or dolomite. All soil amendments should be based on the results of soil tests.

\section{Drainage}

On the Ridge, natural drainage is normally excellent and no further enhancements are usually required. In flatwoods areas, the naturally high water table must be controlled and provision must be made for the rapid removal of excess surface water from rainfall. Control of the water table is achieved via the construction of evenly spaced ditches in addition to beds. In some cases where the depth to hard pan is fairly deep ( $>40$ inches) drain may be employed, particularly in areas where soils are nonuniform. In some areas (particularly DeSoto County), growers routinely install drain tile to control the water table in addition to beds and ditches.

\section{$\underline{\text { Beds and Water Furrows }}$}

Rows are typically oriented north-south and consist of beds constructed with vee-ploughs and/or motorgraders between water furrows that are generally 48 to 55 feet apart. Water furrows are cut 2 to 3 feet deep and the soil is mounded between them to provide a $21 / 2$ - to $31 / 2$-foot bed height from the bottom of the water furrow to the crown of the bed. Beds of these dimensions are the most common and they accommodate two rows of trees 24 to 27.5 feet apart.

Single-row beds are used by some growers but they are becoming increasingly rare due to the problems associated with grove care and harvesting when water furrows are wet. Wider multiple (4 to 6) row beds are sometimes seen, particularly in areas where shallow fractured limestone is encountered. Prior to bedding it is sometimes advantageous to laser-level the land to facilitate rapid surface water removal by the water furrows.

\section{Lateral Ditches}

Lateral drainage ditches should be cut at right angles to the beds and water furrows, and spaced no further apart than 1320 feet. Topsoil spoil from the ditches can be used to provide fill for low areas in the adjoining fields. Subsoil spoil provides a grove road base on either side of the lateral ditch. Water furrows drain into the ditches via 6 to 8 inch flexible polyethylene or rigid pipe that can be installed either before or after water furrow construction. A laser level is sometimes employed in this operation, but is not essential. The pipe is installed in the bottom of the water furrow and sloped to discharge approximately 1 foot above the bottom of the ditch. Ditch size will vary depending upon the area served and other water management district criteria. In general, lateral ditches should have a minimum top width of 14 to 15 feet, bottom width of 4 feet, 2:1 side slopes, and a depth of at least 5 feet.

\section{Collector Ditches}

Drainage water from several lateral ditches runs into collector ditches and is conveyed off-site. Gravity drainage is preferred if topographic relief allows. However, discharge pumps are required where there is insufficient relief. Size of the collector ditches and any related pumping facilities are dependent on several factors such as size of the area being served, soils, bed and water furrow design, and slope of ditches. The surface water drainage system should be designed to remove at least 4 inches per day from the grove.

\section{$\underline{\text { Tile Drainage }}$}

Drain tiles may be installed for additional control of the water table in areas that have suitable depth to the hard pan (see Drainage System Design and Management for Florida Citrus, http://edis.ifas.ufl.edu/CH165). Perforated, 4-inch diameter, flexible polyethylene pipe covered with a nylon fabric sock installed down the center of every other bed normally provides effective control. The 
pipe should be installed on a slope corresponding to the flow of the swales at depths averaging 3 to 4 feet or less, depending upon the location of spodic or clay horizons. Generally speaking, drain tile should not be installed below the depth of the hard pan horizons.

\section{$\underline{\text { Perimeter Grading }}$}

In order to intercept and control the off-site water table and off-site surface flows, it is necessary to construct a perimeter ditch and dike. The dike is located external to the ditch. Frequently the ditches can serve as collector ditches. The actual size of the ditches depends on anticipated flow rates. High water tables or natural drainage from adjacent undeveloped properties may result in subsurface flow towards a grove. Pumps may be required in the perimeter ditches to intercept this seepage water in order to maintain satisfactory water table depths in the developed grove.

\section{Resource Protection and Permitting Considerations}

\section{Threatened or Endangered Species}

The Central Florida Ridge and other well-drained sandy soils in Florida support a unique flora and fauna with a high degree of endemism (species found only in these habitats). Due to the initial, relatively sparse distribution of the habitat types associated with these soils and the rapid conversion of them to citriculture, housing development, golf courses and urban encroachment, many of the species unique to them have been listed as threatened or endangered by federal, state, and local agencies. Consequently, those areas remaining in their natural vegetative state have many development limitations associated with the protection of listed species. Therefore, when selecting land for new citrus plantings, it is often beneficial to select land that has already been cleared for other purposes.

In the Flatwoods, loss of existing, native, upland habitats is of concern in certain areas but generally land clearing regulations are far less restrictive than on the Ridge. In this regard (i.e., land clearing), many County Comprehensive Plans contain exemptions for bona fide agricultural operations. When considering site selection for new grove in
Flatwoods areas, it is still advantageous to procure already cleared land. The best lands for citrus development generally are former row-crop farming areas where land will have been cleared, leveled and have received soil amendments. Before starting site clearing, check with state and local agencies to ensure that the project is consistent with all regulatory criteria.

\section{$\underline{\text { Nutrient Leaching }}$}

Due to the highly permeable nature of Ridge-type soils, the potential for leaching of nutrients and agrichemicals to aquifers is high. Recently, elevated levels of nitrates have been discovered in potable well water on the Ridge. Conscientious use of Best Management Practices (BMPs) in the application of all agrichemicals should be given paramount importance in both new and existing citrus operations in these areas.

\section{Water Use Permits}

Water use is regulated in Florida by five water management districts (WMDs). The districts issue water use permits (WUP) to allocate water for reasonable beneficial uses. Citrus production is considered to be such a use. However, water is generally allocated from lower-quality sources for agricultural uses. Consumptive use permits are granted for fixed periods of time. Duration may not exceed 20 years. However, permits are generally issued for shorter durations because the districts have lacked the information needed to commit the resource for longer periods of time. Permits are revocable only for material false statements, willful violation of permit conditions, and for nonuse of the water supply. Thus, except during times of water shortage or emergency, permittees have full rights to the water specified in their permit.

Reasonable beneficial use is defined as the use of water in such quantity as is necessary for economic and efficient utilization for a purpose and in a manner which is both reasonable and consistent with the public interest. Applicants must present evidence of the quantity of water requested, the need, purpose, and value of the use, and the suitability of the use to the source. The method and efficiency of use, water conservation measures, and the practicality 
of reuse or the use of lower-quality water are also considerations.

Applicants must show the proposed use will not interfere with any presently existing legal use of water. The extent and amount of harm caused, whether that harm extends to other lands, and the practicality of mitigating harm by adjusting the quantity or method of use, also are considered. Any adverse actions from using the water such as water quality degradation or increased flood damage are also factors considered in permit. In the case of groundwater withdrawals, extensive modeling (and sometimes testing) of the aquifers concerned is necessary to achieve this requirement.

The permitted amounts must also be consistent with the public interest. Rules regarding public interest are defined through the rule making process by the Florida Department of Environmental Protection (FDEP) and the water management districts. Generally, consistency with the public interest is determined on a case-by-case basis in the permitting process.

\section{Surface Water Management}

Because drastic changes from pre-construction conditions are generally necessary for water table control and drainage for flatwoods citrus production, the main resource protection concerns center around effects on wetlands and water quality. In addition, changes to surface water discharge rates must be addressed to meet criteria adopted by Florida's WMDs. A surface water management system for citrus production in the Flatwoods should be designed to remove at least 4 inches in 24 hours. However, most native Flatwoods areas drain at rates of 1 inch in 24 hours or less.

\section{Increased Runoff Rates}

Properly designed surface water management systems can achieve adequate drainage with moderate storm water runoff rates. Runoff rates are reduced by designing surface water detention areas that are interspersed between the grove area and the ultimate off-site discharge points. Typically, these are diked-off areas that receive inflow from the grove area either via gravity or pumped discharge. Outflow from the detention areas (often called reservoirs) passes through discharge structures that are designed to restrict the flow rate to predevelopment peak rates. Water levels thus build up in detention areas for a short period of time following major rainfall events. Normally, a registered Civil or Agricultural Engineer must be retained to design a system in order to obtain a permit from the appropriate WMD or other regulatory agency.

\section{$\underline{\text { Water Quality }}$}

Pollutant loadings in the form of sediments and dissolved agrichemicals, including pesticides, can and should be minimized via the use of BMPs. In order to obtain an Environmental Resource Permit from the appropriate WMD, a grove developer must either agree to provide ongoing monitoring of discharge water quality or retain a professional engineer to design a system to meet the criteria for water quality treatment. In most cases this is achieved via detention areas. The detention areas provide attenuation of peak runoff rates and allow the drainage water to be released at lower rates over a longer period. Studies have also shown that the detention areas are effective in providing water quality treatment and improved quality of runoff water.

An alternative form of water quality treatment acceptable to the Southwest Florida Water Management District (SWFWMD) is the use of grassed filter strips. For smaller systems, less than 40 acres, the USDA Natural Resource Conservation Service (NRCS) engineers can provide designs to obtain a so-called permanent agricultural exemption from SWFWMD. For larger systems, a professional engineer must be retained.

\section{$\underline{\text { Wetlands }}$}

The WMDs have a legislative mandate to protect wetland resources. In addition, the U.S. Army Corps of Engineers (COE) regulates direct impacts on wetlands via the discharge or deposition of fill. Both agencies are also tasked with assessing and regulating secondary and cumulative impacts. It is important, therefore, to try to eliminate impacts on wetlands from proposed designs. The issues can be fairly complex and it is usually cost-effective to retain 
consultants to prepare designs and permit applications relative to wetland impact.

Grove design should start with a thorough investigation of predevelopment drainage patterns. Care should be taken to eliminate or minimize diversion of natural watersheds, particularly if they are feeding downstream, off-site wetland systems. Off-site up gradient flows can be taken through projects via natural flow-ways or constructed channels, or they can be taken around projects in constructed ditches provided they outflow at their predevelopment location. Usually off-site flows should be kept separate from project flows because intermingling may make water quality treatment for the entire volume necessary.

Avoiding direct impacts on wetlands can be achieved by setting back development lines to provide an upland buffer. This also eliminates the need to obtain a permit from the COE. When setbacks are large enough, the indirect impact of water table drawdown can be minimized or eliminated. Another benefit is that setbacks may fulfill requirements to incorporate upland buffers to accommodate wildlife. Some WMDs have developed procedures for calculating the setback distance required to avoid drawdown of wetlands.

Incorporation of wetlands in detention areas provides a another way of avoiding wetland drawdown. However, when detention areas are used to reduce peak runoff rates, water levels will rise within them. The maximum safe depth for small impoundments is about 4 feet. However, flooding a natural wetland systems to this depth for prolonged periods will result in damage to the wetland syatem. Therefore, wetland detention areas must be designed to reduce the depth and/or duration of excess inundation to avoid negative impacts.

Directing project discharges to off-site wetlands can counteract the effect of drawdown from adjacent citrus development. When this is done, however, it is important to try to maintain the predevelopment delivery system. That is, if it was via sheet flow, then the project should discharge to a spreader swale to restore such flow prior to entering the wetlands. Maintaining hydraulic head within the water table of an adjacent wetland can be achieved by interposing a detention area between a citrus development and the wetlands.

Incorporating wetlands into natural flow-ways carrying off-site flows through a project can provide for a habitat mix of wetlands and uplands, and connectivity between off-site and on-site undeveloped areas. This also meets the goal of accommodating wildlife species that are sensitive to habitat fragmentation.

\section{Tree and Row Layout}

Tree planting patterns should be selected to provide spacing between trees for ample growth, maximum exposure to sunlight, and good air circulation, as well as to facilitate management, cultural practices, and harvesting operations. Trees are typically planted in a geometric design. The planting system should be selected based on several considerations: slope, maximum use of the land area, final tree size, required spacing between trees, and type of fruit grown. In addition, the space needed for the passage of cultural and harvest equipment is a very important consideration. Generally, the triangular systems are better if the trees are to be allowed to attain their natural size and form (no hedging). However, if distance between rows is more important than distance between trees and if tree rows are to be hedged to control tree size, then the rectangular designs are recommended.

Generally, row orientation should be north-south to maximize exposure to sunlight. North-south orientation is more important for groves that are closely spaced within the rows and for hedgerows. When closely spaced trees are aligned in east-west rows, typically one side of the tree receives significantly more sunlight than the other.

\section{Cold Protection}

There are three basic considerations that determine how cold a grove site will be during a freeze when compared with other sites in the same general area. The first consideration is topography. Cold air is heavier than warm air and drains downhill, collecting in low areas that are often known as pockets. These low areas should be avoided to minimize the cold hazard. A good site for 
development would be adjacent to lower areas into which cold air can drain.

Land elevation and air drainage are the most important factors affecting the temperature in any one location. An elevation difference of as little as 4 feet can cause a temperature difference of as much as $5^{\circ}$ $\mathrm{F}$ on clear nights with little wind movement. In selecting sites for the growing of citrus, consideration should be given to the microclimate of the various areas and types of locations. Weather records and experience attest to the fact that well-drained, high-ground slopes are the most desirable.

Low areas or pockets in the best and warmest citrus areas are often as cold or colder than areas north of the citrus area where it is not profitable to grow citrus. Moreover, citrus in cold pockets in warm areas is often more sensitive to cold than citrus grown farther north because generally warmer winter temperatures will reduce development of cold hardiness.

The second consideration is proximity to large bodies of water. Freezes come into Florida from the north or northwesterly direction. Therefore, groves situated near lakes or large rivers will be afforded some protection by warming of the cold air by the water. Groves located near the Atlantic Ocean or Gulf of Mexico will also be afforded some degree of cold protection by proximity.

The third consideration is latitude or how far south the grove is located in the Florida peninsula. As a generalization, the farther south the grove is located, the less likely it is to be damaged during freeze conditions in Florida. Arctic air masses that bring freezing temperatures to Florida are moderated somewhat as they traverse the length of the state. It is difficult to classify Florida into broad climatic zones based upon the anticipated or historical incidence of freezing temperatures. Each potential site should be appraised separately based upon all considerations.

\section{Irrigation System}

Research since the 1960s has consistently shown that irrigation can significantly increase production on most commercial cultivars. The research has shown that it is critical to maintain relatively high soil moisture levels from the spring flush until the young fruit is at least one inch in diameter. The soil moisture should be maintained so that less than $1 / 3$ of the available water is depleted from the soil during this time. Field capacity is that amount of water remaining in the soil after the excess has drained away. During the remainder of the year, about $2 / 3$ of the available water can be depleted from the soil without adversely affecting production. Irrigation can have an influence on other aspects of citrus production. Generally, irrigation can increase tree size, yield, fruit size, and juice content. Under certain conditions, irrigation can reduce fruit color, soluble solids, acid, and may affect the Brix:acid ratio. Excessive irrigation in the fall can reduce the fruit solids, affecting the net returns.

\section{$\underline{\text { Methods of Irrigation }}$}

Various methods of irrigation have been used in Florida over the years. All have their advantages and disadvantages. However, in recent years, nearly all new groves have had microirrigation systems installed. Freeze protection, rising costs of high pressure systems, and water use limitations placed on growers by water management districts are the primary reasons for the switch to these types of systems.

Portable perforated pipe has almost become a thing of the past due to high labor costs. There are still a few systems still in operation, but these are limited to smaller acreages. The portable and self-propelled volume guns, while still in use in many groves, are losing favor due to the high energy costs. They are inefficient under high wind conditions and are not considered to be effective on bedded groves since much of the water runs off into the furrows and ditches, and is thereby lost to the tree's root zone. In addition, they provide little freeze protection.

Seepage and crown flood irrigation is practiced on Flatwoods areas in the Indian River area and in Southwest Florida. With a proper match of water control structures, ditches, soils, and topography, these types of irrigation can be quite efficient. With this type of system, irrigation and drainage are managed together. This system requires large expensive pumping equipment capable of moving 
large volumes of water. Care must be exercised not to allow water to remain in the root zone for extended periods as damage to the tree root system may occur. Since large volumes of water are required, even though a high percentage of the water is returned to the shallow aquifer and retention ponds, the grower must be able to justify its use to the water management districts. These systems also offer good cold protection as growers can flood the furrows and perimeter ditches during freeze periods.

Permanent overhead sprinkler systems have declined in popularity over the last 20 years due to high fixed costs and inefficiency during periods of high winds. Pop-up tree sprinklers have also lost favor since they are susceptible to damage by grove equipment and impairment of riser movement by sand contamination. High-volume under-tree sprinklers are still used on limited acreage in Florida.

Low-hanging branches interfere with the water distribution pattern of these under-tree systems.

Microirrigation systems have the advantage of lower initial and operating costs as compared to other systems. They operate at lower pressures, reducing energy consumption, and are easily automated. Since lower volumes of water are required, these types of systems can utilize less productive water sources. If operated properly, these systems can minimize water loss due to evaporation and deep percolation below the root zone of the tree. The spray-jet systems offer some degree of cold protection during radiation type freezes. Maintenance of microirrigation systems is needed on a frequent basis. Clogging of emitters by algae, insects, ants, and precipitates can be a major problem with these systems.

\section{$\underline{\text { Pump Units }}$}

The pumping unit must have enough capacity to irrigate all intended zones during the most extreme conditions (such as freeze events). Ideally, all zones should be of about the same size and have about the same pressure requirements because an irrigation pump operates most efficiently at a single flow rate and pressure. The system design should meet all local and state standards, and should be approved by a professional engineer.
Consideration should be given to the pressures required to operate the critical subunit, friction losses through the mainline (including all losses through valves, filters, meters, fittings, etc.), and elevation changes including pumping lift. For surface water supplies and water at pumping levels of less than 20 feet in wells, centrifugal pumps are the most economical option. For water at depths greater than 20 feet in wells, turbine pumps must be used. For large systems, deep-well turbines with power units on the surface are commonly used. For smaller units, submersible turbines are a less expensive option.

With submersible turbines, electric motors are directly connected to the pumps and lowered into the well. For automatic operation, turbine pumps have the advantage in that they do not require priming for the pump to operate (conventional centrifugal pumps require priming). For automatic operation, electric motors are recommended as power units for microirrigation systems. They have lower initial costs than internal combustion engines, especially for smaller sizes. There may be a demand charge on the electric bill for their use, especially for larger units. Most power companies now have off-peak rates for irrigation pumps. Some power companies have also eliminated standby or demand charges for off-peak users. Local power company policies will dictate actual costs.

Diesel power units are the most common type of internal combustion engines used for irrigation in Florida. They are more efficient than other types of internal combustion engines. Internal combustion engines are recommended when irrigation systems will be used for cold protection, because of the possibility of electric power interruption and loss of pumping capability on cold nights.

\section{$\underline{\text { Pump Station }}$}

The pumping station should be protected from the elements as rain can cause moisture in motor windings and direct sun can raise motor operating temperatures significantly. A sturdy shed with a concrete floor provides a clean, dry, well-ventilated environment free of weeds and debris, and is conducive to proper operation and good maintenance. Safety requirements should be considered in the design of the pump station. There may be 
high-voltage power lines, tanks of gasoline or diesel fuel, toxic agricultural chemicals, chlorine solutions, etc. present in or near the pumping site. There may be problems associated with water and fuel spills, leaks in pressurized pipes or discharges from pressure relief valves. The possibility of vandalism, theft, and entry by unauthorized persons should be considered. The mounting for pumps and drivers (motors or engines) should be a sturdy concrete base. For permanent diesel engine installations, construct a concrete mounting isolated from the concrete floor to minimize vibration.

\section{$\underline{\text { Filters }}$}

Filters should always be used on microirrigation systems. Filters remove small particles that may clog the tiny orifices in emitters. The type of filtration system required depends on the type of emitter used and the source and quality of the irrigation water. Filters should be selected based on emitter manufacturer's recommendations. The mesh size selected should be small enough to remove all particles larger than $1 / 7$ th the size of the emitter orifice.

If organic matter is a problem when pumping from surface waters, media (sand) or self-cleaning screen filters should be used as the primary filter. A strainer should be used on the pump intake to exclude as much organic matter as possible. The intake should be positioned below the water surface to avoid floating debris, and above the bottom to avoid pumping sediment from the bottom of the pond or canal. Self-cleaning strainers for the pump inlet are available to prevent larger particles from entering the irrigation system.

When pumping from wells, screen filters alone are normally adequate unless large amounts of sand are being pumped. If large amounts of sand are being pumped, a vortex-type sand separator may be used, followed by a screen filter. Settling basins may also be used to remove large amounts of sand, but basins may cause problems if organic matter such as algae is present in the basins.

$\underline{\text { Valves }}$
Valves are required to control the filling of irrigation systems at pump startup, to control flows to the desired subunits of a system, and to allow flushing of irrigation pipes. Only properly pressure-rated irrigation valves must be used to avoid failures due to system pressure and water hammer problems. Valve materials and components must be resistant to corrosion by the irrigation water and any chemicals injected during irrigation. Valves should be sized to avoid excessive pressure losses. Typically, manual zone valves are the same size as the pipe (or possibly one size smaller if the valves are not operating in series). Installing smaller valves to save initial costs will result in higher operating costs for the life of the system due to friction losses. Automatically-controlled irrigation systems will require the use of automatic valves. These may be controlled by electric solenoids or hydraulic pressures, depending upon the type of timer or controller used. Automatic valves usually require some pressure differential across the valve to operate in a timely manner. Automatic valves should be sized according to the manufacturer's specifications (typically, one size smaller than the pipe).

\section{$\underline{\text { Backflow Prevention }}$}

Florida law requires that a backflow prevention system be installed on most irrigation systems. Backflow prevention systems are always required when chemicals are injected into an irrigation system. The minimum backflow prevention system required when fertilizers or chemicals are injected includes a check valve, low pressure drain, and vacuum breaker on the irrigation pipe to prevent water and chemicals from flowing back to the water source. Florida law also requires interlocked power supplies to prevent chemical injection unless the irrigation water is flowing, a check valve on the injection line to prevent water flow to the chemical supply tank, and a positive shutoff valve on the chemical tank to prevent accidental drainage from the tank.

When chemical toxicity Category I pesticides are injected into irrigation systems, a double check valve, low-pressure drain, and vacuum relief valve assembly are required. These pesticides are marked with the keywords Danger or Poison on the label. The Environmental Protection Agency (EPA) requires 
that all pesticide products be labeled to clearly state whether injection into irrigation systems is permitted. Pesticide labels must also list the backflow prevention equipment requirements and application instructions.

\section{Chemical Injection Equipment}

Pressurized irrigation systems are often used to apply chemicals, especially fertilizers. Growers can obtain yield increases and minimize leaching losses (and pollution) by injecting nutrients and other chemicals through the irrigation systems. Many growers currently inject fertilizer through sprinkler and microirrigation systems. Chemical injection equipment is required to add the correct amount and rate of chemical. Several types of chemical injectors are commercially available ranging from the low-cost venturi devices to high-cost positive displacement pumps. If a high degree of precision is required (such as for pesticides), more precise injection methods must be used. These include the high-precision but more costly positive displacement injection pumps such as diaphragm- and piston-type pumps. Microirrigation systems require high-precision chemical injection pumps to precisely control biocides and water amendments used to prevent emitter plugging.

\section{$\underline{\text { Irrigation Controllers }}$}

Irrigation controllers are devices which automatically turn the irrigation system, and associated equipment such as chemical injection pumps, on and off. Controllers are not mandatory for system operation, but they are time and laborsaving devices. They are especially economical and efficient for management of microirrigation systems on Florida's sandy soils because of the requirement for frequent irrigations. Controllers range in capabilities from simple timers which can turn a single valve on and off at preset times, to computers that allow remote control of pumps, valves, and control devices at several locations. Computer controllers can collect data from sensors, make calculations and adjust water and chemical application schedules in response to plant needs and environmental conditions.

\section{Emitters}

The emitter selection process should consider uniformity as well as other factors such as cost, wind effects, system constraints, maintenance, tree density, and soil type so that the best emitter for a particular field condition is selected. The wetting pattern of emitters needs to be compatible with the soils and rooting pattern of the trees. Emitters with distinct spoke patterns may not be as efficient as more uniform patterns where shallow root systems and very sandy soils are encountered. Consideration also must be given to the water requirements of the mature tree. Higher density plantings with smaller trees will require less water per tree than more widely spaced trees. Larger wetting patterns may be more desirable for more widely spaced trees. In all cases, designers should ensure that tree water requirements can be met with reasonable run times, and not result in percolation of nutrients and water below the root zone.

Protection during severely cold freezes can be improved by using a higher application rate. For young trees, this can be done by changing from a $360^{\circ}$ to a $180^{\circ}$ or $90^{\circ}$ spray pattern. While a high application rate may be beneficial for freeze protection, this is not necessarily desirable for normal irrigation during the rest of the year. A high application rate can also lead to leaching of nutrients and pesticides. Application rate can be increased by increasing emitter output and decreasing spray pattern size. With small diameter spray patterns and moist soil, irrigation duration of one hour or more can drive water below the main root zone. By adjusting spray diameter, irrigation duration, and emitter output, microirrigation systems can be managed to meet tree water needs while reducing overirrigation and chemical leaching.

The need for a high application rate for freeze protection and a lower application rate to reduce chemical leaching means that there may not be an ideal microsprinkler that provides adequate freeze protection, good root zone coverage, and reduced chemical leaching. Nevertheless, with knowledge of the factors involved, emitters can be chosen that will perform all these functions reasonably well. 


\section{Benefit Cost Analysis}

The decision to plant citrus in many areas of Florida can be made even more complex due to issues related to water management. Irrigation systems can positively influence both fruit quantity and quality, but are not inexpensive undertakings. The decision to invest in a high performance irrigation system can be difficult to evaluate, but must be included as part of the overall citrus production strategy. Project evaluation provides a means of evaluating the positive benefits versus the costs of undertaking a given project. In other words, project evaluation determines empirically whether projects are worthwhile economically. One way to evaluate an irrigation project's value is to conduct a benefit cost analysis.

The objective of a benefit cost analysis (BCA) is to determine if the projected benefits from implementation of a proposed project exceed the projected costs within a stated time frame. While BCA is commonly used to evaluate publicly funded projects, it can also be used to evaluate private investments. The BCA calculation should be the final determinant as to whether a project should be undertaken.

Benefit Cost Analysis examines the net benefits of a project, recognizing that dollars earned and costs incurred in the future must be discounted to current values. BCA also allows for evaluation over any time frame within the life expectancy of the project, and is accomplished through calculation of the project's Net Present Value (NPV). If net present value (NPV) is greater than zero, the project benefits exceed project costs and can justifiably be undertaken. NPV can be calculated by the following (Eq. 1):

$$
\operatorname{NPV}_{t}=\sum_{t=0}^{T} \frac{F_{t}}{(1+r)^{t}}
$$

where,

$$
\begin{aligned}
& \mathrm{F}_{\mathrm{t}}=\mathrm{B}_{\mathrm{t}}-\mathrm{C}_{\mathrm{t}}=\text { net benefits accruing in year } \mathrm{t} \\
& \mathrm{B}_{\mathrm{t}}=\text { benefits accruing in year } \mathrm{t} \\
& \mathrm{C}_{\mathrm{t}}=\text { costs accruing in year } \mathrm{t}
\end{aligned}
$$

$\mathrm{T}=$ last year the project influences productivity

$\mathrm{r}=$ discount rate (usually the interest rate)

\section{Example:}

An irrigation project is proposed with a 20 -year life expectancy. The lending institution is concerned that the project is too expensive and will not pay for itself quickly enough. Conduct a BCA for the first 5 years for a discount rate of $6 \%$. Benefits and costs are given in Table 1. The NPV is calculated using Eq. 1 as:

$$
\begin{aligned}
& \mathrm{NPV}=\sum_{\mathrm{t}=1}^{5} \frac{\mathrm{F}_{\mathrm{t}}}{(1+\mathrm{r})^{\mathrm{t}}}=\frac{\mathrm{B}_{\mathrm{t}}-\mathrm{C}_{\mathrm{t}}}{(1+\mathrm{r})^{\mathrm{t}}} \\
& =\frac{0-50,000}{(1+.06)^{1}}+\frac{8,000-15,000}{(1+.06)^{2}}+\frac{10,000-10,000}{(1+.06)^{3}} \\
& +\frac{15,000-5,000}{(1+.06)^{4}}+\frac{1,800-5,000}{(1+.06)^{5}} \\
& =\frac{-50,000}{1.06}+\frac{-7,000}{1.124}+\frac{0}{1.191}+\frac{10,000}{1.262}+\frac{13,000}{1.338} \\
& =-47,169.81-6,227.76+0+7,923.93+9,715.99 \\
& =-\$ 35,757.65
\end{aligned}
$$

In this example, the net present value is negative indicating that the irrigation project costs exceed the benefits during the five-year period of analysis. If the investment parameters require a positive NPV within the first five years, the BCA indicates that the irrigation project should not be done.

\section{References}

Haeussler, E.F., Jr. and R. Paul. 1993. Introductory mathematical analysis. 7th ed. Prentice-hall, Englewood Cliffs, N.J.

Randall, A. 1987. Resource economics. 2nd ed. Wiley, N.Y. 
Table 1. Annual costs and benefits for proposed irrigation system.

\begin{tabular}{||c|c|c||}
\hline Year & Costs & Benefits \\
\hline $\mathbf{1}$ & $\$ 50,000$ & $\$ 0$ \\
\hline $\mathbf{2}$ & $\$ 15,000$ & $\$ 8,000$ \\
\hline $\mathbf{3}$ & $\$ 10,000$ & $\$ 10,000$ \\
\hline $\mathbf{4}$ & $\$ 5,000$ & $\$ 15,000$ \\
\hline $\mathbf{5}$ & $\$ 5,000$ & $\$ 18,000$ \\
\hline
\end{tabular}

